\title{
Bandwidth Extension of BJT Amplifier using a Novel Cascade Topology
}

\author{
Rupjyoti Haloi \\ Department of Electronics and Communication \\ Engineering, Gauhati University, \\ Guwahati-781014, Assam, India
}

\author{
Kandarpa Kumar Sarma \\ Department of Electronics and Communication \\ Engineering, Gauhati University, \\ Guwahati-781014, Assam, India
}

\begin{abstract}
In any amplifier design, it is always necessary to give utmost attention to its frequency response analysis. While applying frequency response for some application it is also important to extend the bandwidth of an amplifier. Increasing the bandwidth means increasing the upper $3 \mathrm{~dB}$ frequency and decreasing the lower $3 \mathrm{~dB}$ limit. Although there are different means by which this extension can be achieved, we have chosen the application of negative feedback for the purpose. We have derived some new topologies from these existing topologies which fulfill our bandwidth requirements. In this paper, we are presenting a new approach based on the individual standard topologies which extend the bandwidth of the standard amplifier by $30 \%$.
\end{abstract}

Keywords: - Frequency response, bandwidth, negative feedback, $3 \mathrm{db}$ frequency.

\section{INTRODUCTION}

Conventional BJTs have limited frequency response range. In any amplifier design, it is always necessary to give utmost attention to its frequency response analysis. While applying frequency response for some application it is also important to extend the bandwidth of an amplifier. Increasing the bandwidth means increasing the upper $3 \mathrm{~dB}$ frequency and decreasing the lower $3 \mathrm{~dB}$ limit. There are several approaches by which this range can be extended [1] [2]. An extended range allows use of the BJT based system for multiple applications. A simple approach to extend the bandwidth of the BJT amplifier is the use of negative feedback. Such works have already been explored and studied extensively [1] [2]. Another approach is to combine multiple feedback configurations and derive additional benefits. Here, we discuss such an approach. We have analyzed the detail frequency response provided by composite structures formed using combinations of known feedback topologies. The work includes detailed theoretical analysis of the proposed topology and responses to various parameter variations considered. The theoretical analysis show that the proposed approaches provides considerable improvement in bandwidth expansion and enables multiple frequency dependent applications. Experimental works suggest that cascade topologies provide improved performance. Especially series shunt - shunt shunt topology provides the best bandwidth expansion. Compared to series-shunt topology, the proposed approach provide $30 \%$ betterment while in comparison to shunt shunt topology, the improvement is $22 \%$.
Some of the relevant literatures are [1] to [20]. The rest of the paper is organized as below: Secion 2 provides certain theoretical consideration. Section 3 includes the proposed model. Experimental details are included in section 4 and Section 5 concludes the paper.

\section{THEORETICAL BACKGROUND}

Most physical systems incorporate some form of the feedback. Feedback can be either positive (regenerative) or negative (degenerative). Negative feedback has the advantages of desensitizing the gain of the amplifier, reducing nonlinear distortion, reducing the effect of noise, controlling the input and output impedances and extending the bandwidth of the amplifier. In amplifier design negative feedback is applied to effect one or more of its above mentioned properties. Although based on the quantity to be amplified and on the desired form of output amplifier can be classified into four categories. For the present work we are using series-shunt and shunt-shunt type of feedback amplifiers. Figure. 1 shows a common-emitter amplifier with series - shunt type of negative feedback.

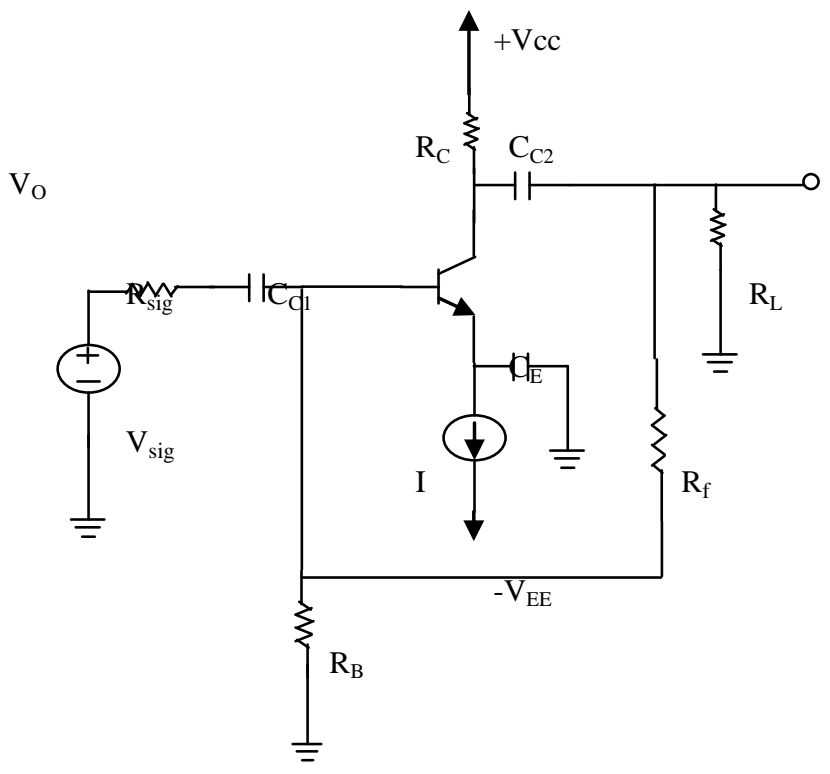

Figure 1: Series-shunt type of feedback amplifier

The high frequency equivalent circuit of the amplifier is shown in figure 2 : 


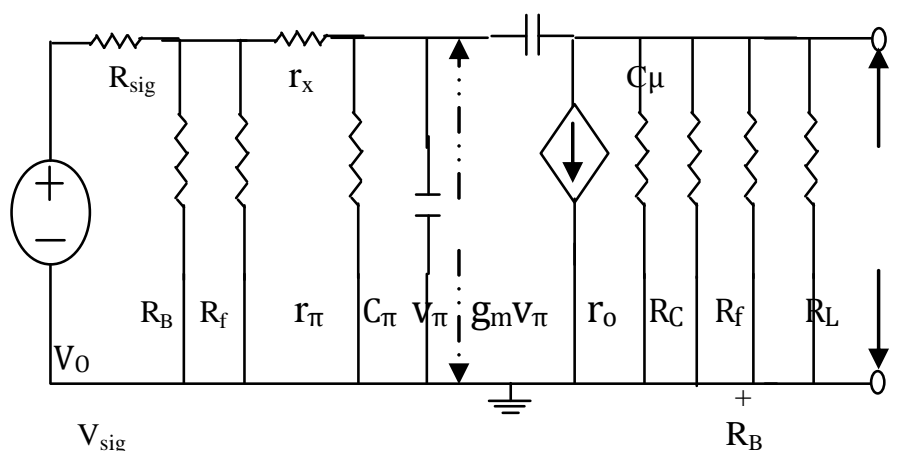

Figure 2: High frequency equivalent circuit

Figure 3 shows the common emitter amplifier with shuntshunt type of negative feedback.

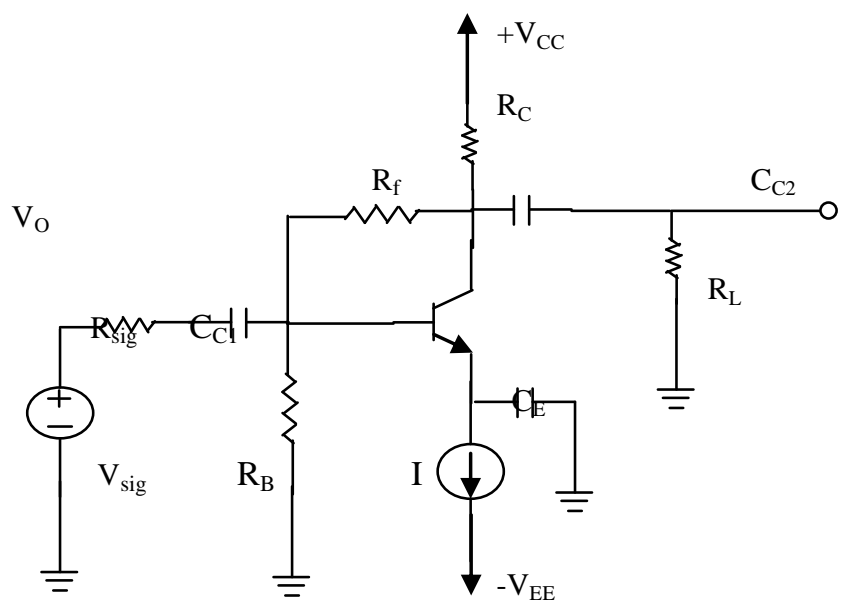

Figure 3: Shunt shunt type of feedback amplifier

The working of the system is already known. The high frequency equivalent circuit of this circuit is shown in figure 4.

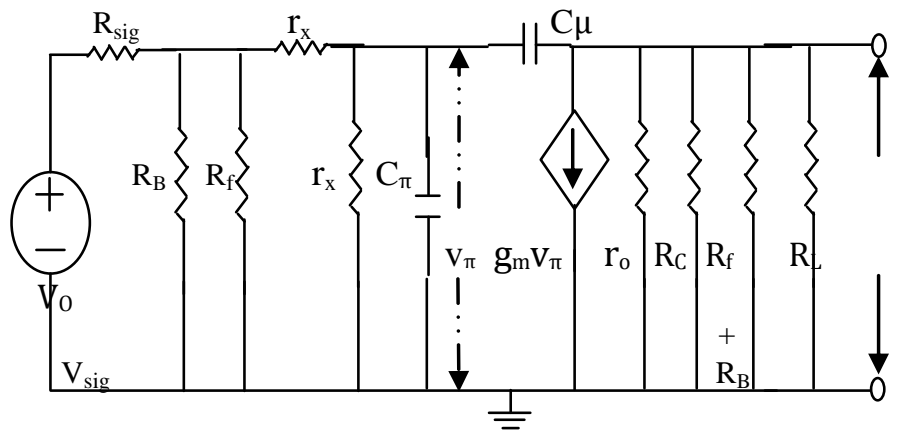

Figure 4: High frequency equivalent circuit

From these equivalent circuits, we can derive the mathematical

equations for calculation of the high cut-off frequency. The high frequency $f_{H}$ can be calculated by using the following expression:

$$
f_{H}=\frac{1}{2 \times \pi \times C_{i n} \times R_{s i g}^{\prime}}
$$

where input capacitance,

$$
\begin{aligned}
& C_{i n}=C_{\pi}+C_{e q} \\
& =C_{\pi}+C_{\mu}\left(1+g_{m} R_{L}{ }^{\prime}\right) \ldots \ldots \ldots . . . \\
& R_{\text {sig }}{ }^{\prime}=r_{\pi} I I\left\{r_{x}+\left(R_{B}^{\prime} / / R_{s i g}\right)\right\} \\
& \text { and, } R_{B}{ }^{\prime}=R_{B} / / R_{f}
\end{aligned}
$$

Again for low frequency analysis we are using the circuit shown in figure 5 with the dc sources eliminated.

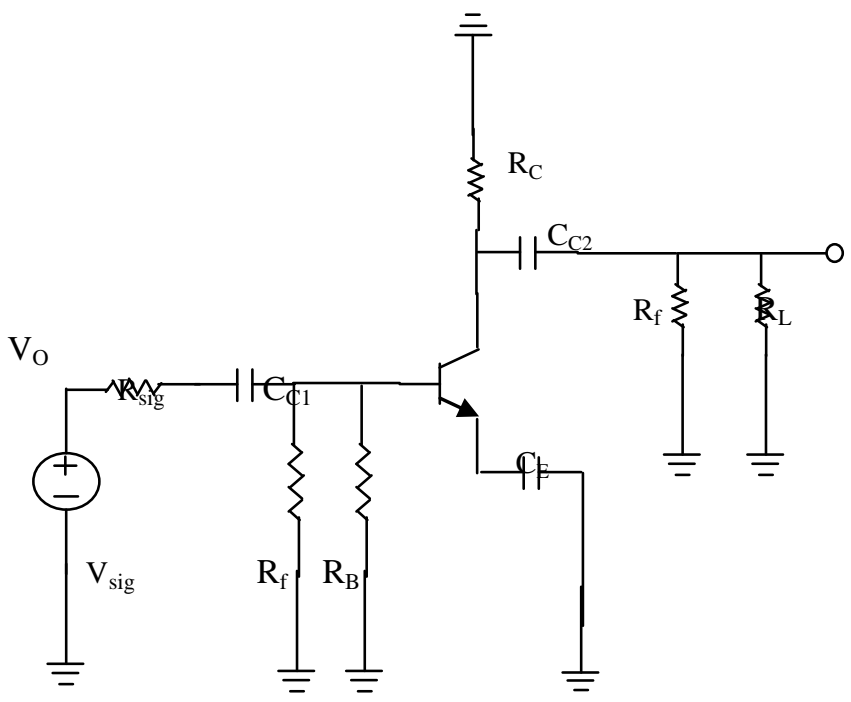

Figure 5: Amplifier circuit for low frequency analysis

We can perform the small signal analysis directly on the circuit. For this low frequency analysis, we can ignore $C_{\pi}$ and $\mathrm{C}_{\mu}$ since at such a low frequency their impedances will be very high and thus can be considered as open circuit. Also, in this analysis, we are neglecting $r_{x}$ and $r_{\pi}$ as their effects on the amplifier response at low frequency are very small.

For finding out the lower cut off frequency, we consider the three capacitances $\mathrm{C}_{\mathrm{C} 1}, \mathrm{C}_{\mathrm{C} 2}$, and $\mathrm{C}_{\mathrm{E}}$ one at a time considering other two as perfect short circuits. By this procedure three break frequencies $f_{1}, f_{2}$ and $f_{3}$ are found. From these three break frequencies, we can calculate the low cut-off frequency by using the expression

$$
\begin{array}{r}
f_{L}=\frac{1}{2 * \pi}\left[\frac{1}{C_{C 1} R_{C 1}}+\frac{1}{C_{E} R_{E}}+\frac{1}{C_{C 2} R_{C 2}}\right] \\
=f_{1}+f_{2}+f_{3} \ldots \ldots \ldots \ldots \ldots \ldots \ldots \ldots \ldots \ldots
\end{array}
$$

where $\mathrm{C}_{\mathrm{C} 1}, \mathrm{C}_{\mathrm{C} 2}$ and $\mathrm{C}_{\mathrm{E}}$ are the capacitances as shown in figure and $\mathrm{R}_{\mathrm{C} 1}, \mathrm{R}_{\mathrm{C} 2}, \mathrm{R}_{\mathrm{E}}$ are the resistances as seen by $\mathrm{C}_{\mathrm{C} 1}, \mathrm{C}_{\mathrm{C} 2}$ and $\mathrm{C}_{\mathrm{E}}$ respectively. These resistances can be calculated by using the following expressions:

$$
R_{C 1}=\left(R_{B} / / r_{\pi}\right)+R_{s i g}
$$


$R_{E}=r_{e}+\frac{R_{B} / / R_{\text {sig }}}{\beta+1}$

$R_{C 2}=R_{C}+R_{L}$

\section{PROPOSED MODEL}

Based on the theoretical analysis stated above in Section 2, we propose here this new composite model. It is shown in figure 6.
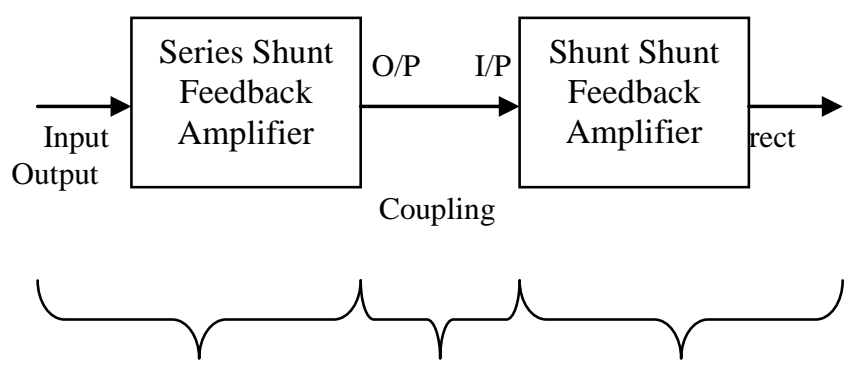

Input Stage Intermediate Stage Output Stage

Figure 6: Block diagram of the proposed model

Here, we are cascading series-shunt and shunt-shunt type of feedback amplifiers. For cascading these two amplifiers, we are using here the method of direct coupling. Direct coupling connects two amplifier stages by taking the output of the first stage as the input of the second without the use of capacitors. The equivalent circuit for this cascaded topology is shown in figure 7 .

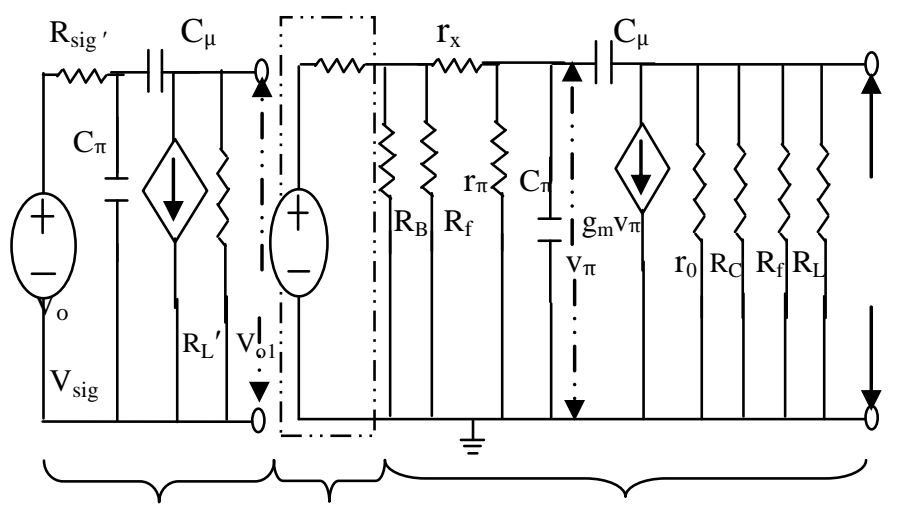

\section{Series-Shunt Direct Coupling Shunt-Shunt}

Figure 7: equivalent circuit of the proposed model

In this proposed model, the output voltage of the series-shunt amplifier will act as input to the shunt shunt type of feedback amplifier. From this equivalent circuit, the high frequency can be calculated by the expression

$$
f_{H}=\frac{1}{2 \times \pi \times C_{i n} \times R_{s i g}{ }^{\prime}}
$$

where,
$R_{s i g}{ }^{\prime}=r_{\pi} I I\left\{r_{x}+\left(R_{B} / / R_{f} / / R_{L}{ }^{\prime}\right)\right\}$

In this expression, $r_{\pi}, r_{x}, R_{B}, R_{f}$ and $C_{i n}$ are calculated from the output stage and $\mathrm{R}_{\mathrm{L}}{ }^{\prime}$ is the equivalent output resistance of the first stage of the amplifier. We can calculate the low frequency by the expression

$$
f_{L}=\frac{1}{2 * \pi}\left[\frac{1}{C_{C 1} R_{C 1}}+\frac{1}{C_{E} R_{E}}+\frac{1}{C_{C 2} R_{C 2}}\right]
$$

where,

$$
\begin{aligned}
& R_{C 1}=\left(R_{B} / / r_{\pi} / / R_{f}\right)+R_{s i q} \\
& R_{E}=r_{e}+\frac{R_{B} / / R_{s i g}{ }^{\prime}}{\beta+1} \\
& R_{C 2}=R_{C}+R_{L}
\end{aligned}
$$

Here $R_{\text {sig }}{ }^{\prime}$ is the output resistance of the first stage of the composite amplifier topology.

\section{EXPERIMENTAL DETAILS AND RESULTS}

For selecting the best possible 2's-configuration form, we calculate the input and output impedances of all the possible configurations. The behavior of those topologies based on these results are shown in Table 1. From Table 1, we can clearly select series shunt - shunt shunt type of cascaded topology to be the most suitable one. Here input and output impedances increases which leads to better performance.

Table 1. Characteristics of the possible two configuration form of the standard topologies.

\begin{tabular}{|l|l|l|l|l|l|c|}
\hline \multicolumn{5}{|c|}{ Cascaded topology } & $\begin{array}{c}\text { Input } \\
\text { Impedance }\end{array}$ & $\begin{array}{c}\text { Output } \\
\text { Impedance }\end{array}$ \\
\hline Series & Shunt & - & Shunt & Series & Increases & Increases \\
\hline Series & Shunt & - & Shunt & Shunt & Increases & Decreases \\
\hline Series & Shunt & - & Series & Series & Increases & Increases \\
\hline Shunt & Series & - & Shunt & Shunt & Decreases & Decreases \\
\hline Shunt & Series & - & Series & Series & Decreases & Increases \\
\hline Shunt & Shunt & - & Series & Series & Decreases & Increases \\
\hline
\end{tabular}

With the help of the equivalent circuits and the derived expressions, we have calculated $\mathrm{f}_{\mathrm{H}}$ and $\mathrm{f}_{\mathrm{L}}$ and also the bandwidth. The results are tabulated in Table 2 . We see that the Series-Shunt Shunt-Shunt configuration with $1062 \mathrm{KHz}$ provides $30 \%$ bandwidth expansion compared to Series Shunt topology. 
Table 2. Results of the bandwidth calculation

\begin{tabular}{|c|c|c|c|}
\hline Feedback type & $\begin{array}{c}\text { frequency } \\
\mathrm{f}_{\mathrm{L}}(\mathrm{Hz})\end{array}$ & $\begin{array}{c}\text { frequency } \\
\mathrm{f}_{\mathrm{H}}(\mathrm{KHz})\end{array}$ & $\begin{array}{c}\text { Bandwidth } \\
\left.\mathrm{f}_{\mathrm{H}}-\mathrm{f}_{\mathrm{L}}(\mathrm{KHz})\right)\end{array}$ \\
\hline Series- shunt & 162 & 817 & 816 \\
\hline Shunt -Shunt & 142 & 874 & 873 \\
\hline $\begin{array}{l}\text { Series shunt } \\
\text { Shunt shunt }\end{array}$ & 137 & 1063 & 1062 \\
\hline
\end{tabular}

For generating the results shown in Table. 2 we assumed some standard values for all the necessary parameters like resistances and capacitances. From the above results, we see that the bandwidth of the cascaded topology is higher than the individual type of amplifier topologies. For better analysis of the frequency response of these amplifiers, we are presenting some tabulated data which show changes in bandwidth with different parameters changes. These are shown in Tables 3 to 5.

Table 3: Bandwidth for different resistances in series shunt topology

\begin{tabular}{|c|c|c|c|c|}
\hline \multicolumn{2}{|c|}{ Resistances } & \multicolumn{3}{|c|}{ series-shunt } \\
\hline $\mathrm{R}_{\mathrm{B}}$ & $\mathrm{R}_{\mathrm{C}}$ & $\mathrm{f}_{\mathrm{H}}$ & $\mathrm{f}_{\mathrm{L}}$ & $\mathrm{BW}$ \\
\hline $100 \mathrm{~K} \Omega$ & $8 \mathrm{~K} \Omega$ & $817.6 \mathrm{~K} \mathrm{~Hz}$ & $162 \mathrm{~Hz}$ & $817.4 \mathrm{KHz}$ \\
\hline $100 \Omega$ & $10 \Omega$ & $135.9 \mathrm{MHz}$ & $5.85 \mathrm{~K} \mathrm{~Hz}$ & $135.9 \mathrm{MHz}$ \\
\hline $300 \mathrm{~K} \Omega$ & $100 \mathrm{~K} \Omega$ & $538.7 \mathrm{KHz}$ & $149 \mathrm{~Hz}$ & $538.6 \mathrm{KHz}$ \\
\hline $500 \mathrm{~K} \Omega$ & $200 \mathrm{~K} \Omega$ & $523.4 \mathrm{KHz}$ & $148 \mathrm{~Hz}$ & $523.3 \mathrm{KHz}$ \\
\hline
\end{tabular}

Table 4: Bandwidth for different resistances in shunt shunt topology

\begin{tabular}{|c|c|c|c|c|}
\hline \multicolumn{2}{|c|}{ Resistances } & \multicolumn{3}{c|}{ shunt - shunt } \\
\hline $\mathrm{R}_{\mathrm{B}}$ & $\mathrm{R}_{\mathrm{C}}$ & $\mathrm{f}_{\mathrm{H}}$ & $\mathrm{f}_{\mathrm{L}}$ & $\mathrm{BW}(\mathrm{Hz})$ \\
\hline $100 \mathrm{~K} \Omega$ & $8 \mathrm{~K} \Omega$ & $874.5 \mathrm{KHz}$ & $142 \mathrm{~Hz}$ & $874.4 \mathrm{KHz}$ \\
\hline $100 \Omega$ & $10 \Omega$ & $135.9 \mathrm{MHz}$ & $5.832 \mathrm{KHz}$ & $135.9 \mathrm{MHz}$ \\
\hline $300 \mathrm{~K} \Omega$ & $100 \mathrm{~K} \Omega$ & $608.4 \mathrm{KHz}$ & $130 \mathrm{~Hz}$ & $608.3 \mathrm{KHz}$ \\
\hline $500 \mathrm{~K} \Omega$ & $200 \mathrm{~K} \Omega$ & $595.7 \mathrm{KHz}$ & $128 \mathrm{~Hz}$ & $595.6 \mathrm{KHz}$ \\
\hline
\end{tabular}

Table 5. Bandwidth for different resistances in series shunt - shunt shunt topology

\begin{tabular}{|c|c|c|c|c|}
\hline \multicolumn{2}{|c|}{ Resistances } & \multicolumn{3}{c|}{ series shunt - shunt shunt } \\
\hline $\mathrm{R}_{\mathrm{B}}(\Omega)$ & $\mathrm{R}_{\mathrm{C}}(\Omega)$ & $\mathrm{f}_{\mathrm{H}}$ & $\mathrm{f}_{\mathrm{L}}$ & $\mathrm{BW}(\mathrm{Hz})$ \\
\hline $100 \mathrm{~K} \Omega$ & $8 \mathrm{~K} \Omega$ & $1063.5 \mathrm{KHz}$ & $137 \mathrm{~Hz}$ & $1063.3 \mathrm{KHz}$ \\
\hline $100 \Omega$ & $10 \Omega$ & $328.5 \mathrm{MHz}$ & $50.2 \mathrm{KHz}$ & $328.4 \mathrm{MHz}$ \\
\hline $300 \mathrm{~K} \Omega$ & $100 \mathrm{~K} \Omega$ & $630 \mathrm{KHz}$ & $155 \mathrm{~Hz}$ & $629.8 \mathrm{KHz}$ \\
\hline $500 \mathrm{~K} \Omega$ & $200 \mathrm{~K} \Omega$ & $611.3 \mathrm{KHz}$ & $150 \mathrm{~Hz}$ & $611.2 \mathrm{KHz}$ \\
\hline
\end{tabular}

The results conclusively show that cascade topologies provide improved performance. Especially series shunt - shunt shunt topology provides the best bandwidth expansion. Compared to series-shunt topology, the proposed approach provide $30 \%$ betterment while in comparison to shunt shunt topology, the improvement is $22 \%$.

\section{CONCLUSION}

Here, we have presented a new topology that gives a higher bandwidth compared to the standard individual topologies. Also we have presented a detail theoretical analysis of the amplifier frequency response with respect to the different values of the amplifier's internal and external parameters. These analyses would help us in achieving better performance from the amplifier.

The theoretical analysis show that the proposed approaches provides considerable improvement in bandwidth expansion and enables multiple frequency dependent applications. Experimental works suggest that cascade topologies provide improved performance. Especially series shunt - shunt shunt topology provides the best bandwidth expansion. Compared to series-shunt topology, the proposed approach provide 30\% betterment while in comparison to shunt shunt topology, the improvement is $22 \%$.

\section{REFERENCES}

[1] D. A. Neamen: Electronic Circuits:- Analysis And Design, $3^{\text {rd }}$ ed. ,The McGraw Hill Companies , New York, 2007

[2] A. S. Sedra, K. C. Smith:- Microelectronic Circuits: Theory and Applications, $5^{\text {th }}$ ed., Oxford University Press, London, 2004.

[3] S. Salivahanan, N. S. Kumar, A. Vallavaraj:- Electronic Devices and Circuits, $2^{\text {nd }}$ ed., Tata Mc-Graw Hill Publication, new Delhi, 2008.

[4] R. Samadi, M. A. I. Karsilayan, J. Silva-Martinez: "Bandwidth enhancement of multi-stage amplifiers using active feedback", Proceedings of the 2004 International Symposium on Circuits and Systems, Vol.1, pp. 609-612, 2004.

[5] S. Goswami, T. Copani, B. Vermeire, H. Bamaby: "BW extension in shunt feedback transimpedance amplifiers using negative miller capacitance", IEEE Journal on Circuits and Systems, pp. 61-64, 2008.

[6] W. R. MacLean: "Ultimate Bandwidths in High-Gain Multistage Video Amplifiers", Proceedings of the IRE , Vol.32, no.1, pp. 12-15, 1944.

[7] C. Ciofi, F. Crupi, C. Pace, G. Scandurra : "How to enlarge the bandwidth without increasing the noise in OP-AMP-based transimpedance amplifier", IEEE Transactions on Instrumentation and Measurement, Vol.55 , no.3, pp. 814-819, 2006.

[8] S. Shekhar, J. S. Walling, D. J. Allstot: "Bandwidth Extension Techniques for CMOS Amplifiers", IEEE Journal of Solid-State Circuits, , Vol. 41 , no 11, pp. 2424-2439, 2006.

[9] D. P. E. Dale: "Video amplifiers for video display units", IEEE Colloquium on Linear Analogue Circuits and Systems, pp. 1-8, 1992. 
[10] G. Bruun: “ Common-Emitter Transistor Video Amplifiers", Proceedings of the IRE Vol. 44 , pp. 15611572, 1956 .

[11] D. Comer: "Video amplifier design based on op amps", IEEE Transactions on Circuits and Systems, Vol.23 , pp. 169-171, 1976 .

[12] W. Ballentine, F. Blecher : "Broadband transistor videoamplifiers", Solid-State Circuits Conference. Digest of Technical Papers. Vol.II , no. 4.4, pp. 41-43, 1959.

[13] N. Charalampidis, K. Hayatleh, B.L. Hart, F.J. Lidgey : "A wide bandwidth voltage-follower with low distortion and high slew rate", 13th IEEE International Conference on Electronics, Circuits and Systems , pp. 256-259, 2006.

[14] C.B.Yahya : "Design of wideband low noise transimpedanceamplifiers for optical communications", Proceedings of the 43rd IEEE Midwest Symposium on Circuits and Systems Vol. 2, pp. 804 - 807, 2000.

[15] P. Gajjar, N. Bhatt, Y. Kosta : "Artificial Bandwidth Extension of Speech \& Its Application in Wireless Communication Systems: A Review", International Conference on Communication Systems and Network Technologies, pp.563-568, 2012.
[16] E.-S.A.M.Hasaneen, M.A.A. Wahab, N. Okaley: "Bandwidth Extension of CMOS Transimpedance Amplifier using On-Chip Spiral Inductor", $2^{\text {nd }}$ International Design and Test Workshop, pp.43-46, 2007.

[17] L. Haojie, B. Changchun, L. Xin, Z Xingtao, Z Liyan : "Audio Bandwidth Extension Based on RBF neral network" , IEEE International Symposium on Signal Processing and Information Technology, pp. $150-154$ 2011.

[18] H. Pulakka , L. Laahsonen , V. Myllyla , Y. Yrttiaho , P. Aiku : "Conversational Evaluation of Speech Bandwidth Extension using a Mobile Handset", IEEE Signal Processing Letters, vol.19, no.4, pp.203-206, 2012.

[19] A. Mahato, K. K. Sarma : "A Few Topologies for UWB Low Noise Amplifier Design", Journal of Instrument Society of India, vol.42, no.2, June. 2012.

[20] A. Mahato, K. K. Sarma : "Stability of Feedback Based LNA Topologies for UWB Communication”, IFRSA International Journal of Electronic Circuit and Systems, vol.1, no.2, July.2012. 